\title{
Teaching and Learning English Language through Literacy Drive Policy in Grade 3 in Public Schools: Teachers' Perception and Challenges
}

${ }^{1}$ Umaira Aleem, ${ }^{2}$ Dr. Sadia Irshad

${ }^{1} \mathrm{PhD}$ Scholar, Air University Islamabad

${ }^{2}$ Assistant Professor, Air University Islamabad

*Corresponding Author: umaira.aleem6@gmail.com, sadiyairshad@gmail.com

\begin{abstract}
This paper investigates the place of pedagogy in language-in-education policy through an analysis of how the macro-level government policy interacts with the micro-level English language teaching practices. Since 2015, the teaching and learning of English language to grade 3 students, in all public schools of the Punjab, has been carried out through a literacy and numeracy drive called LND. The present study investigated the effectiveness of teaching English to grade 3 through literacy drive policy (LDP) of LND programme. It locates the implementation of LDP, in language in acquisition policy perspective and supports the stance that language teaching and learning is central to language planning and policy research (Johnson, 2013; Menken \& García, 2010). It argues that language interventions deployed at any level of education are extension of language education policies which aim to improve the quality of education and to promote the learning of the language. Like all language in acquisition policies, LDP for teaching and learning of English is being executed in the same context of increasing the number of language users through teaching of foreign or second language (Cooper, 1989). The study investigated perceptions of teachers regarding teaching and learning of English through LDP with the notion that effective implementation of any language programme is linked with the understanding and practices of teachers who are the real implementers and final arbiters at micro level (Menken, 2008). The present study included a portion of data from my $\mathrm{PhD}$ dissertation. It collected teachers' experiential standpoints to explore teachers' awareness regarding implementation of LDP and issues they face inside the classrooms when they carried out teaching learning of English through LDP. The findings of the study revealed that teachers teaching English to grade 3 lack awareness in terms of clear understanding regarding LDP mainly because it is less elaborated and not accessible. It ultimately hindered the successful implementation and poses multiple classroom challenges.
\end{abstract}

Keywords:

English Language, Literacy Drive Policy, Grade 3, Public Schools

Article Received: 18 October 2020, Revised: 3 November 2020, Accepted: 24 December 2020

\section{Introduction}

English enjoys the elite status in Pakistani linguistic hierarchy(Abbas, Pervaiz \& Arshad, 2018). On one hand, it is the language of power, civil administration, trade, commerce, judicature and armed forces (Abbas, 1993; Abbas \& Iqbal, 2018). On the other hand, it is the principal language of Pakistani education system (Channa, 2017). In the state run schools of Pakistan, the academic vista projects the status of English as a compulsory subject and medium of instruction in alternative language in education and national education policies (NEP, 2009; NEP, 2017). During Mushraf's era in 1999, the educational landscape of Pakistan saw a major revamp. The English language endorsed its status as a compulsory subject from grade 1 and medium of instruction in all state run schools (Mahboob,
2002).The initiation of the English language as compulsory subject from grade 1 is directly linked with the goals of Education For All (EFA) 2015 and Education Sector Reforms (ESR) agenda: “(i) to promote quality education" (USAID, 2008, p. 1). These reforms were further evolved and reflected in national education policies (NEP 2009, NEP 2017). The discourse of promotion of quality education also found its place in provincial educational strategies (Abbas, Jalil, Zaki \& Irfan 2020). Under the flagship of school reforms roadmap, the education setup in state run schools of Punjab was also refurbished (Anjum, 2020). These reforms were named as 'Barho Punja,Parho Punjab' and launched in 2015 to improve quality of education and to set a direction to achieve educational targets (enrollment, academic facilities, educational facilities) till 2018(Dawn, 
2015). As part of the Chief Minister's (CM) education roadmap, the School Education Department Punjab (SED), with the collaboration of the Department for International Development (DFID) launched a comprehensive school monitoring dashboard called 'Quality Drive'. Later, with the help of Pakistan Information of Technology Board (PITB) the Quality Drive was scaled up as digitized Literacy and Numeracy drive generally known as LND and implemented in grade 3 of all public schools across the Punjab. Apart from DFID's agenda, the commitment of SED is also linked directly with the goal-4 of SGD (Sustainable Development Goals) 2030, focuses on "inclusive and equitable quality education and lifelong learning for all" and demands the surety that "all youth and a substantial proportion of adults, both men and women, achieve literacy and numeracy" by 2030 (UNESCO, 2019).Furthermore, 'The New Deal 2018-2023' (SED, 2018), the new education policy in the Punjab also outlined the language in education reforms at primary level (Iqbal \& Bashir, 2020). The LND is also part of this ongoing education policy.

To achieve the Students Learning Outcomes (SLOs) prescribed for teaching and learning of English in grade 3, the LND programme is ascribed with certain directions, official decisions, standing operating principals (SOPs). The researcher termed these guiding principles for teaching and learning of English language as Literacy Drive Policy (LDP). The study locates the implementation of LDP, in language in acquisition policy perspective. It supports the stance that language teaching and learning is central to language planning and policy research (Johnson, 2013; Menken \& García, 2010). It argues that language interventions deployed at any level of education are extension of language education policies which aim to improve the quality of education and to promote the learning of the language. Secondly, like language in acquisition policies, LDP for teaching and learning of English is being executed in the same context of increasing the number of language users through teaching of foreign or second language (Cooper, 1989).

The activity of teaching and learning of English SLOs through LDP in grade 3 is combined with an android application. The application is integrated with a comprehensive multiple choice question bank for English subject. To practice teaching and learning through LDP, every school in the Punjab is provided with an android tablet. The teaching and learning through LDP is linked with a third party evaluation mechanism across all public schools in the Punjab. The Monitoring and Evaluation Assistants (MEAs) who are the retired armed personnel, visit all public schools monthly. Along with checking a school's performance as per CM road map indicators, he takes spot test of the randomly selected $7-10$ students of grade 3 on the provided official android tablet. From an inbuilt LND application, the MEA selects questions and assesses the proficiency of students in English subject on his own tablet (PITB, 2020). The teaching and learning of English through LDP has prioritized SLOs as a unit of measure in terms of students' performance against expected standards of learning in the subject of English. The assessment result is reflected as part of key performing indicators (SED, 2020) in the monthly data pack (Fig-1) as benchmarks to record the improvement in district wise quality of education in terms of teaching and learning (Literacy Drive Government of Punajb, 2019) . 


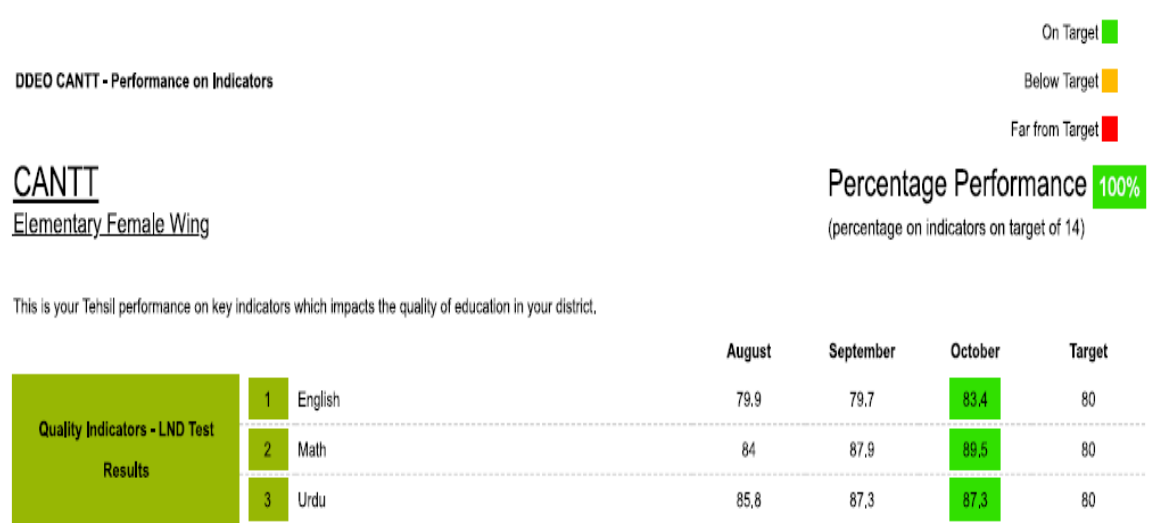

The significance of teaching and learning of English through LDP is evident from the fact that on monthly basis 329,000 grade 3 students of 47,000 public schools in all 36 districts of Punjab are being assessed in three subjects particularly in English for basic and advance key learning outcome (Punjab Information Technology Board, 2020). These include use of different forms of the verb, identification of simple words with correct spellings, identification and articulation of correct action word, punctuation, simple sentence formation by using SV, interaction with text and use of reading strategies, use of kinds of adjective, use of alphabetical order, identification of common and proper nouns, articulation and identification of words containing blends, digraphs and tri-graphs and preposition and identification of articles

(Fig-2).

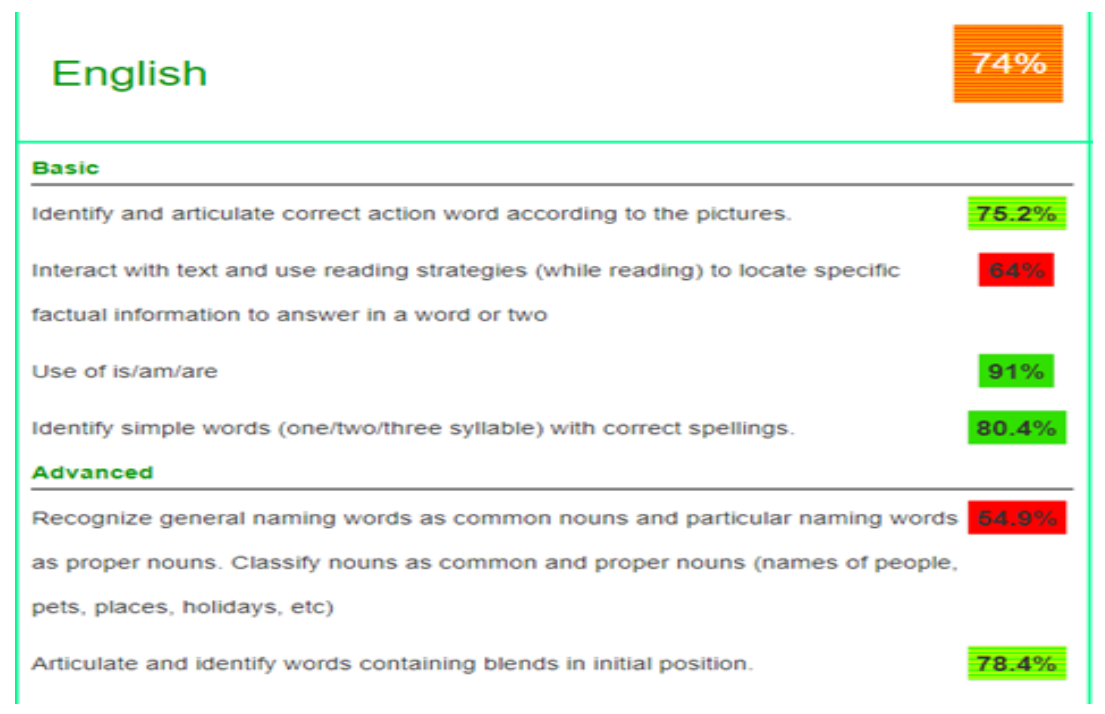

Fig-2

Though the mechanism of teaching, learning and evaluation of the English language through LDP seems very systematic, only 63 percent students of grade 3 of government schools "can read at least words" and " $31 \%$ class 3 children could read class 2 level sentences..." (Idara-e-Taleem-o-Aagahi, 2020).It established the fact that as a compulsory subject, English has been taught at all levels without considering who teaches it, in what manner and to whom. This dilemma connects the teaching learning of English to the misapprehension of language in education policy and planning by the policy executers. Therefore, it was necessary to explore the voice of teachers regarding their understanding of LDP and challenges they face during teaching and learning of English language through LDP. The investigation from teachers' perspective was pertinent for two reasons. First, teachers are the core language policy agents and they interpret, implement and appropriate language in education policies inside the classrooms (Johnson, 2013, p.108) .Second, they are the "final arbiter(s) of the 
language education policy and its implementation" (Mohanty, et al 2010, p.228).

The proposed study maintains that if the effective implementation of teaching and learning through LDP is required, the plight and potential of the teachers teaching English to grade 3 cannot be left unaddressed. For this purpose, the present investigation focuses on exploration of awareness, choices and practices carried by the teachers which they hold as actors of the execution of literacy drive as policy of teaching, learning and assessment of English language skills at core level in classrooms.

The study inquires:

1. What are the teachers' experiential standpoints about the LDP and the directions it necessitates for teaching and learning of the English language in grade 3?

2. How is the LDP as language in acquisition policy for teaching and learning of the English language actualized by teachers inside the classrooms?

3. What difficulties do teachers realizing LDP face while teaching English in grade 3?

The body of the reviewed literature shows that LND has been analysed so far only from the perspectives of computer mediated learning particularly English language learning and use of technology inside the classroom (Khan \& Mansoor, 2020). The findings of a study(Ishaq, Mat Zin, Rosdi, Abid, \& Farooq, 2019) revealed that LND as an English language software was not effective due to lack of technological resources at students' homes, language problems, irrelevant content, method of assessment, operational design of the software and usability. The study was conducted from students' perspective and the voice of teacher was missing in that study.

Ishaq et al. (2020a, 2020b, 2020c) investigated the usability and usefulness of LND specifically as a mobile assisted language learning and evaluation application from the perspective of teachers, students and district managers. By keeping in view the users' experiences, reliability and functionality of LND, the study concluded that
LND is not effective and useful both in terms of content and usability. Though the studies (Ishaq et al., 2020b, 2020c) were conducted from students and teacher's perspectives, the questions asked from the students were abstract and beyond the understanding of a 7 years old student. For instance to investigate the usability, ease of use of LND application suggestions for the improvement in the application the students were asked: "Do you think that content of English learning is suitable in LND application?" Do you think the method of assessment adopted in LND is suitable for you?" and "Do you think Interactive Screen and Icons are not available in LND application for you to learn English?" Another study informed that the teaching of English through LND could be improved if unhealthy environment, lack of facilities, influence of mother tongue and noncooperation of parents found some solutions (Lodhi et al., 2019). The study recommended the need of improvement in LND mechanism for better outcome but it did not talk about the policy behind the mechanism and teacher's understanding about it.

The review of the relevant studies regarding LDP implementation identified the theoretical and methodological gaps in existing body of the knowledge. Firstly, the previous studies carried out investigation of LND programme in technological and pedagogical terms, secondly the studies focused only on the surface activity and they did not link the usage ; pedagogy and teachers' perspectives with the planning, directions and objectives of this educational plan. Therefore the proposed study picked up the missing strand and tended to explore the implementation of LND in terms of policy and planning perspective to investigate the understanding and experiences of teachers regarding the implementation of LDP.

\section{Methodology}

The proposed study is based on the data collection for thesis. It is qualitative in nature. Drawing upon the focused group discussion, this study documents teachers' perspectives and 
understanding regarding teaching and learning of the English language through LDP.

For the present study, 20 female teachers were selected from rural and urban primary and elementary schools from Cantt area of district Lahore, through random sampling. The data collected for one round of focus group discussions have been analyzed in this study. The discussion with the help of assistant moderator was conducted in Urdu and it lasted from 45 to 60 minutes. The views of teachers were audiorecorded, transcribed for the study and also documented through the field notes. The excerpts and quotations from the transcription were translated in English to validate the research findings and discussions. To maintain the anonymity of the respondents, the researcher termed all teachers as participants and no reference has been used.

By deploying the inductive approach, the data were analyzed through the constant comparison by incorporating open, axial and selective coding (Strauss \& Corbin, 1998). Initially the transcribed data were clubbed into small units (open coding) and each unit was labelled with a descriptor. At the second step, these small units of data were arranged into categories (axial coding) through lexical and all these categories were categorized into the themes developed through the analysis (selective coding).

\section{Discussion and Findings}

\section{Understanding of teachers regarding teaching of English through LDP}

The participants shared their perception regarding teaching and learning through LDP in terms of its features, syllabus and purpose. They considered LDP as learning of English skills and grammatical rules. Some took LDP as translation, spellings and understanding. The discussion also revealed the knowledge of teachers regarding student learning outcomes specified for teaching and learning through LDP.

The participants are uncertain about total number of SLOS included in the syllabus of English. According to one participant there are 32 SLOS for English whereas the other considered them 6 in numbers. Another respondent divided SLOS into 'fixed' and 'new' categories. For the participants the fixed SLOs are based on the content of the syllabus repeatedly coming since the start of the session. Whereas the new SLOs include English items coming every month distinctively. Disagreed with this perception, one participant opined:

"From the start[ of the session] is/am/are were coming repeatedly but now excluded while action words are included since the beginning but now they have become a constant feature from 2-3 months" P14/MPhil.

The teachers get information about these SLOs from social media for instance from the widely circulated through the Whats App messages and from the updating of LND application. The participants highlighted a pressing issue about the unguided content of the SLOs:

"This is the problem, first the SLOs should be provided and we don't know the SLO beforehand. For instance, the month of March would start, if we get the SLO [for the month of March] on $1^{\text {st }}$ of March, the MEA takes test on $2^{\text {nd }}$ of March. Now tell what the student and teacher can do" P14/MPhil. In addition to this, they do not get content of test from educational managers and LND supporting sites for instance PITB, and open Punjab:

"This is the very drawback [of spot test] that we know nothing. If any teacher or school discuss [their monthly assessment] in group, we come to know about the content, otherwise we have no information"P3/ MSc.

\section{Understanding of teachers about Literacy and numeracy Material ( LITNUM )routine}

There were different responses of teachers regarding LITNUM hour. Some called it 'book reading', some associated it with literacy and reading activities, dictation and stories. The teachers were not aware about the LITNUM English specific features and directions regarding it. One of the participants viewed it as: 
"There are show and tell, keywords, story or poem and concept time. There are new keywords and brain games" $\mathrm{P} 1 / \mathrm{MSc}$.

\section{Link between LITNUM hour and LND English SLOs:}

The discussion reveals that there is no link between LITNUM hour routine and LND SLOs for English. The LITNUM content does not support learning through LND, nor does it support any SLO:

"LITNUM [the content] does not support LND [teaching and learning], we make our students practice on tablet or board, we only use these two things [as teaching aids]" P9/M.Ed.

The participants were of the view that the display of LITNUM routine in the classes is only to fulfil the 'indicator'. Furthermore, the lesson plans and reflective notes which are also part of LITNUM routine are not synchronised with the daily teaching and practice of English through LDP. Teachers prepare reflective notes for SLOs without implementing them through their teaching:

"We do write reflective notes but we don't apply them in class" P4/ MSc. It shows teachers have no guidance regarding the integration of lesson plan, teaching of SLOs and reflective notes formation.

\section{Implementation of LITNUM hour in classroom:}

One of the participants denies any implementation of LITNUM hour inside the classroom. The LITNUM hour routine is applicable in Math classes not in English subject classes. One participant claimed that she implemented LITNUM hour routine at the start of the session when it was part of monthly indicators. It means only those practices are adopted for which there is a fear of monitoring. The participants implemented LITNUM hour routine in many adapted ways. One participant preferred book reading instead of storytelling and composing a vocabulary book. She shared problems while applying this adapted routine: first, it took one complete hour to practice reading activity; second, all students cannot read as they are not of same learning level. She left this LITNUM hour routine because the SLOs specified for English subject cannot be achieved if this routine would remain continued. It shows that teachers have not been guided properly how LITNUM hour and LITNUM routines of reading, vocabulary bank, and showing and telling are linked with SLOs specified for English.

\section{Perception of teachers regarding test mechanism by MEA:}

The discussion revealed that teachers have not been informed about the SOPs of the monthly LND English assessments taken by the MEA. The discussion revealed ongoing practices of tests in different grade 3 classroom settings.

\section{Selection of the students:}

Teachers have no choice to present well prepared students for the test. The MEA calls students' name from attendance register or call them for test on his own choice. One participant informs about the practice of the MEA that he just takes spot test on tablet. Only few MEAs inspect SLO charts, LITNUM hour display, key word notebook and sometimes they check last month test.

\section{Time allocation for test}

It is also pertinent to know that teachers do not know about the prescribed test time for the test. They informed that the MEA winds up test and all other monitoring in grade 3 within 15 minutes. Teachers don't know about the time allocated for each student for assessment, as they are not allowed to participate even as a silent observer: "They [the MEAs] even don't allow us to stand beside and if we say: Sir, give some time to the student, he knows how to attempt this question [on tablet] they say, no, we don't have enough time, we have to visit the next school" P5/ BS.

\section{Challenges of the spot test taken by MEA for English}

In teachers' point of view, the Mea is not competent enough to take this spot test. He 
cannot guide teachers about weak areas nor is he able to do scaffolding for the relevantly weaker students during the test session:

"[The] MEA has no role in the test, he just swipes the test on the tablet" P14/MPhil.

Another participant informed:

'[In presence of the MEA] the students are under confident, resultantly the student takes pressure and takes wrong attempts.'

The test which MEA takes and the practice tests for English in LND application are entirely different in content. The participants complain that they never know for which SLO their students are being assessed:

"We have no idea whether SLOs are difficult as we cannot have access to those SLOs and the SLOs [in MEA's tablet] are completely different..." P13/M.Ed.

\section{Mode of English test by MEA}

Teachers prefer paper pencil based test if LND is deemed necessary. In teachers' opinion, tablet can only provide an attraction for learning, but it is difficult for the students to utilize it for assessment:

"Though tab fascinates the students, when sir [the MEA] comes [to take a test] the students lose their confidence. If school teacher takes a test, the students would perform well but the outsiders should not take assessment" P1/MSc.

The teachers also suggested that the online test should be taken by the teachers who would visit school monthly so that students can get familiar with the teacher.

\section{Criterion of selection of students for test:}

According to the discussion the MEA selects 7 students on his choice from the whole class for the test. The teachers asked for an increase in the number of student for the test:

"If he [the mea] picks up 7 students, out of those 7 students, 4 are confused, you can say they are completely blank. They would perform poorly in spot test, resultantly our percentage would get lower" P1/MSc. For the selection of the students, the participants suggested:
" $50 \%$ students should be of MEA's choice and 50 percent should be of teacher's choice" P6/MS.

Teachers also suggested amendments in MEA's SOP of selection of students for the spot test. One participant suggested that the MEA should not select all the under-confident and weak students for the spot test. The selection of students should be flexible. Instead of taking the test from 7 students, more students of grade 3 should be assessed.

\section{Time allocation for test:}

It is also pertinent to know that teachers don't know the prescribed time for completion of test. They informed that MEA would wind up test on tablet and all other grade 3 inspection within 15 minutes. The haste suggests that MEA's mechanism of monitoring and evaluation is unprescribed and unsystematic at policy implementational level. If 15 minutes is the stipulated time for the spot test, the teacher should be guided to design pre spot practice session within this time. But teachers are unaware about the designated time of the test as they have no directions to determine the time the student will need to take the test.

\section{Mixed questions of literacy and numeracy in test:}

The participants also supported the stance that spot test should not be taken for English, Math and Urdu collectively. The SLOs of each subject should be separated so that students can easily attempt all questions:

"They [the MEAs] consider student a computer, at one moment s/he is doing multiplication, the next moments/he is dealing with comprehension, all SLOs are mixed" P7/MPhil.

\section{Different version of English test application in school and MEA's tablet:}

The respondents considered the difference of version of test application for android tablet a big obstacle in effective learning and implementation of LDP. The test is made up of altogether different 
item banks with which the students are not familiar:

"There must be same version of application both for student and for the MEA" P9/ M.Ed.

\section{No Participation of teacher in the test:}

According to the teachers, their participation in the test is necessary. The MEA does not allow teachers to observe the test procedure. It affects the students' performance.

\section{Content of English SLOs for the test:}

The discussion revealed that no version for test has been prescribed for teaching and practice of SLOs for English subject. The teachers have installed version 8 for teaching and practice of English subject SLOs. When the teachers were asked about the content for practice, they mentioned they use tablets and personal phones for practice but they were not sure about the version of application:

“...version $8 \ldots$ currently version 8 is in use ... it has all SLOs" P16/MSc.

\section{Unlimited Content:}

Another participant shared the drawback of the programme:

"Syllabus is vast and unlimited. It is neither according to the mental level of the students nor are their families capable to make them learn at home" P1/MSc. The spot test content also poses issues for the students' comprehension. The SLO of picture recognition has images with confusing options: "The content confuses the students" P13/M.Ed. Another participant shared the confusion regarding unlimited content. She was of the opinion that even if they follow version 8 SLOs, the spot test is not based on those SLOs, the version only helps in familiarizing student with new SLOs:

"We are not sure about the SLOs, it is very difficult for us, and it is unlimited and unseen..." P1/MSc. The teachers demanded visibility of the English content: "The test should be of what we are teaching to the students. The syllabus should be planned and known... there should be similarity what we are practicing from the tablet, the test should be similar to that content. The content in MEA's tablet is entirely different" P13/M.Ed.

\section{Provision of English SLOs syllabus:}

The participants opined that the syllabus of English SLOs must be provided for the whole year. The SLOs must be divided monthly:

"For achieving better results, the SLOs [for English] have to be made permanent" P14/M.Phil. Due to transition of SLOs the improvement in learning outcomes cannot be done:

"The SLOS should be changed in three months instead of getting changed on monthly basis" P11/M.Ed.

\section{Provision of annual syllabus breakup:}

The teachers demanded a defined syllabus for teaching and learning of English so that students can practice accordingly. They are of the opinion that unseen syllabus cannot work for all SLOs.

"...we should be provided with the set [syllabus], rules or spellings. For instance [we should be informed that] these 50 [words] or 100 [words] spellings are included which your students would learn...but the problem is that they give completely unseen [syllabus] test ... we make our students memorize 100 spellings [words] but they give test from 200 words for which we have not been guided."P7/MPhil.

\section{Effectiveness of LDP is linked with screening and pre LDP classes in grade 2}

The participants upheld varying opinions regarding effectiveness of teaching English through LDP. The students with average learning capacity can only get through this language acquisition planning:

"Syllabus is beyond the mental level of the student, secondly it is unlimited. If syllabus would be limited, students would learn what they would be taught" P8/ MA . There should be screening of students prior their promotion to grade three. 
The teachers also linked effectiveness of teaching through LDP with the teaching of basic SLOs in grade 1 and 2:

"It [teaching English through LND] should be as restricted for grade one and two as it is for grade three" P15/ M.Phil.

\section{De facto policies of teachers to actualize LDP for teaching and learning of English:}

Since teachers have not been guided nor provided with proper resources, for instance SLO calendar and syllabus breakup for English, during the discussion it was revealed that to make their students learn through LDP, they have devised their own strategies.

Teachers use their personal resources as teaching aids:

"Now at every month there are new SLOs, we have been provided with one tablet in school. In addition to this, we have also installed LND app [application] in our personal phones" P13/M.Ed.

Moreover, teachers prepare students for 'unseen' English test by deploying a speculated, selfdesigned syllabus in teaching. They teach students action words, identification of objects and spelling from different content. Teachers themselves strive to 'discover' the content after the online test of English. Some teachers strategized maximum practice on whiteboard:

"So that the whole class can get involved in it, through board the students can look and see, so that they can watch [see] and learn for instance spellings" P14/ MPhil.

The de-facto strategies also indicate that teachers have no concept about pedagogy regarding LDP. Some teachers go for direct practice on tablet and rote learning. Whereas others keep practicing previous month SLOs when they don't get access to the current month SLOs. One teacher uses language of instruction as a pedagogical tool to implement her adapted strategies of teaching. She teaches English in Urdu and makes students write in notebooks in Urdu. She further proceeds towards test and practice on tablet. The teachers have also divided their time to teach English according to LDP in their own ways. Different experiences emerged during the discussion. One teacher used to take one hour class of English and she used to cover all SLOs by giving students two questions for each SLO. Whereas another teacher disagreed and called this practice not implementable for English teaching:

"But you cannot apply it in English ......how have you applied? You have to make student learn spellings, unlimited spellings" P1/MSc.

The adapted syllabus also poses difficulties for teachers and students to get through the MEA test: "There is an SLO of verb. I wrote verb from the whole book for if the verbs [in spot test] would come from the book, I could prepare students for it. When the MEA assessed students for verbs; all verbs were changed. He asked me what you teach to the students, what could I say" P3/MSc.

The content of the book and the content of LND English are not synchronised. Even the LND application does not contain all SLOs for monthly test. One participant says that teachers are confused for "LND mechanism is not clear" P1/MSc. The teachers view spellings, picture recognition as basic SLOs that should be taught in grade one and two. On the other hand, the teachers teaching English to grade one and two have not been guided about these SLOs. This wide disconnection of syllabi and absence of guidance put English teaching, learning and assessment through LDP to grade three in a vacuum.

\section{Challenges of the LDP English classroom:}

The teachers face problems for using tablet. Most of the time the tablet is not charged, it is in low battery mode when it is required for the practice session.

\section{Non-provision of Resources for teaching English through LDP}

Resources provided by the management are scarce. The school is provided with tablet only and to support the teaching and learning through tablet no guiding material has been provided to English teachers.

Non provision of results of spot tests: 
The teachers are not provided with any feedback after the MEA takes the monthly spot test. Neither class-wise nor the school wise result is shared with the teachers. They do not have access to any online source to check the performance of their students. For this reason, the teachers remain unaware regarding the performance of their students and also the area of improvement remains unknown to the teacher:

"We should be informed about the weak areas of our students", "We should know in which area [SLO] our students are committing more mistakes" P12/M.Ed.

\section{School support to improve result:}

The head teachers check lesson plans only as a procedure. They don't guide teachers how to improve results of the single spot test or focus on the weak SLO. It seems that heads are also unaware about the SLOs on which the spot test of a month is based. Similarly the heads and teachers have the same level of awareness, being the prime stakeholders of the implementation of LDP they are not provided with the results and weak areas for improvement.

\section{Specified SLOs and students' compatibility}

The participants were of the opinion that the SLOs for English specified for grade 3 students are not according to their mental compatibilities. They further shared that the whole class is not of the same learning caliber:

"No, they [the SLOs] are not according to their mental level. Secondly, the whole class is not of same learning level. We have 67 students, among them there are 20 to 25 students only who pick [the concept] or learn, they have a family background, the family focuses on studies of students. Other students are quite challenging"P6/MS.

Teachers also supported the continuation of the spot test, learning and teaching through LDP with some recommendations:

"It [the teaching learning through LDP] should continue, but the syllabus should be according to the mental level of the students and it should be limited so that they can learn despite just cramming" P8/MA.

\section{Rural Urban divide and inability of students:}

The respondents share that the selection of the SLOs can be justified for the grade 3 students of the urban public schools but these SLOs are beyond comprehension of the students in rural settings.

\section{Mother tongue Influence:}

The students cannot perform equally to achieve all SLOs for the reason that English is not their first language. Even if the students can understand Punjabi or Urdu, they can perform well:

"...some can understand Urdu and some Punjabi but the areas in which we are teaching, students speak in Maiwati, where there is no distinction between 'seen'(س) or 'sheen' (ش).....they cannot comprehend Urdu language even" P3/MSc.

\section{Absence of Suitable learning environment at home}

The students are not provided with learning support at home and in rural schools:

"In those areas teachers don't have access [to all learning resources] and parents also have no access"P6/MS. The students can perform well only where parents give response for their children's learning.

\section{Unavailability of any academic learning targets to be achieved for English SLOs other than spot test}

No learning target for the complete academic session is set to judge students' performance. The teachers only know a few things about monthly English test percentage. For some, the learning target is 80 percent for some it is the 'green' colour coding of overall monthly results. One participant shared the confusion:

"The LND [English], [through which] we are teaching, we have no idea that at which percentage our results would be okay [satisfactory] or at which percentage we would receive a call from the AEO or Dy. DEO" P2/ 
MSc. Another participant complained for not accessing the results:

"You can know percentage only when you have access to results [results are not shared]" P1/MSc.

\section{Policy for selection of teachers to teach English:}

The responses inform that there is no specific criterion for the selection of teachers. The policy is silent regarding selection of teachers for grade three English teaching. The participants have different opinions on the basis of ongoing practices of selection of teacher for grade three English:

"One who comes through transfer, and one who is docile that teacher takes LND [class].The teacher who is argumentative doesn't take LND [class]." In some schools the teachers who have done masters in English, they have been assigned this task of teaching P6/MS.

\section{No specialised training to teach English according to LDP:}

The participants shared that no training before handing over grade 3 for teaching English was given to them. No official guidelines were provided about the deployment of tablet, version of LND application, content of test and syllabus:

"Those who designed LND [programme], though they have designed it well but they did not design its implementation. They neither guided us [the teachers] in the beginning nor did they do resourcing. The information just happens suddenly and we gradually get familiar with it" P13/M.Ed.

The participants also claim that though they have no background of English teaching and experience of English language teacher; they can teach English well. The challenges they face other than the lack of appropriate specialized training are overcrowded classrooms and promotion of the students without any screening. It is pertinent to note that school education department has 100 percent promotion policy and open admission policy throughout an academic session. It implies that students of different learning levels get promoted to grade 3 and throughout the year any student can get admission in grade 3 without any screening.

\section{Medium of instruction for teaching English:}

Teachers got no particular direction for the use of language while teaching English as a subject. Most of them teach English in Urdu.

\section{Conclusion:}

The findings and recommendations indicate that LDP as language in acquisition plan is not being implemented effectively mainly because the policy makers have ignored the voice of teachers whose practices inform the plans at micro level. Secondly, LDP is less elaborated and less integrated. For instance, there is no integration between LITNUM hour routine, English SLOs, English textbook content. In addition to this, the final exam is taken from textbook whereas throughout the year students practice answering question from LND practice tests. These disjointed practices are promoting ineffective learning. The unavailability of defined syllabus, clear directions and disintegration of all the major elements of LDP are creating multiple challenges for teachers for its implementation and appropriation. Moreover, the discussion also confirms that teachers have not been guided and provided with the understanding of the SLOs and the syllabus for LND English. The findings of the present investigation affirms results of the studies (Ishaq, Mat Zin, Rosdi, Abid, \& Farooq, 2019; Lodhi et al., 2019) in terms of ineffectiveness of LND as a language learning drive. The study under discussion also confirms that irrelevant content, issues of usability, lack of resources and mother tongue issues poses hindrance in learning through LDP. The present study analyses these issue from LPP perspective and it concludes that LDP for teaching and learning of English must be reflected in curriculum of English for grade 3. Furthermore, the MEA test mechanism should be part of the literacy drive policy. The monthly literacy test should be scheduled instead of random assessments by the MEAs. There must be 
a defined syllabus and timeline to teach and practice these SLOs and scheduled day of test for MEA so that the students can be assessed for the real learning. The discussion confirms that teachers have not been guided and provided with the understanding of the SLOs and the syllabus for LND English.

\section{REFERENCES}

[1] Abbas, S. (1993). The power of English in Pakistan. World Englishes, 12(2), 147-156. doi:10.1111/j.1467-971X.1993.tb00017.x

[2] Ahmed, S., Abbas, F., Jalil, M. K. \& Ahmad, M. (2019) Language Anxiety as a Detrimental Factor in English Language Learning: A Survey of Religious Madaris. Al Qalam, 24 (2), 346-363.

[3] Anjum, K. (2020). A comparative study of written communication skills of 8th grade students of public, private and missionary schools. Competitive Educational Research Journal (CERJ) 1 (2), 1-12.

[4] Abbas, F. \& Iqbal, Z. (2018). Language Attitude of the Pakistani Youth towards English, Urdu and Punjabi: A Comparative Study. Pakistan Journal of Distance and Online Learning, 4 (1), 199-214.

[5] Abbas, F., Jalil, M. K., Zaki, H. N. \& Irfan, F. (2020). Implicit measure of language attitude: study of Punjabi native speakers by using matched guise technique. International Journal of Innovation, Creativity and Change, 13 (1), 194-206.

[6] Abbas, F., Pervaiz, A. \& Arshad, F. (2018). The competing status of Urdu and English after declaration of Urdu as official language in Pakistan. Journal of Research (Urdu), 34 (1), 142-158.

[7] Channa, L. A. (2017). English in Pakistani public education. Language Problems and Language Planning, 41(1), 1-25.

[8] Cooper, R. L. (1989). Social change. Language planning and social change, 164-182. doi:10.1017/cbo9780511620812.011
[9] Dawn. (2015, March 31). 'Parho Punjab barho Punjab' scheme launched. Dawn. Retrieved from https://www.dawn.com/news/1172958

[10] Idara-e-Taleem-o-Aagahi. (2020). Annual status of education report ASERPAKISTAN 2019. Retrieved from ASER Pakistan secretariat Idara-e-Taleem-oAagahi (ITA) website: http://aserpakistan.org/document/aser/2019/ reports/national/ASER_National_2019.pdf

[11] Iqbal, B. \& Bashir, I. (2020). An analysis of relationship between English and Urdu reading skills of secondary school students in Multan. Competitive Educational Research Journal (CERJ) 1 (2), 13-25.

[12] Ishaq, K., Azan, N., Rosdi, F., Abid, A., \& Ali, Q. (2020). Usability of mobile assisted language learning app (b). International Journal of Advanced Computer Science and Applications, 11(1), 354-363.

[13] Ishaq, K., Mat Zin, N. A., Rosdi, F., Abid, A., \& Ali, Q. (2020b). Usefulness of mobile assisted language learning application a. International Journal of Engineering and Advanced Technology, 9(3), 518-525. doi:10.35940/ijeat.b4549.029320

[14] Ishaq, K., Mat Zin, N. A., Rosdi, F., Abid, A., \& Ali, Q. (2020c). Usefulness of mobile assisted language learning in primary education (c). International Journal of Advanced Computer Science and Applications, 11(1), 384-395.

[15] Ishaq, K., Mat Zin, N. A., Rosdi, F., Abid, A., \& Farooq, U. (2019a). Effectiveness of literacy \& numeracy drive (LND): A students' perspective. Paper presented at 2019 International Conference on Innovative Computing (ICIC), University of Management and Technology, Lahore.

[16] Johnson, D. C. (2013). Findings. In C. N. Candlin \& D. R. Hall (Eds.), Language Policy (pp.98-117). New York, NY, England: PALGRAVE MACMILLAN. 
[17] Khan, A. B., \& Mansoor, H. S. (2020). Integrated Collaborative Learning Approach (ICLA): Conceptual framework of pedagogical approach for the integration of language skills. Competitive Social Science Research Journal, 1(1), 14-28.

[18] Literacy Drive Government of Punjab. (2019, December). EDO Scorecard. Retrieved from https://literacydrive.punjab.gov.pk/reports/e do_scorecard?month $1=12 \% 2 \mathrm{C} 2019$

[19] Lodhi, M. A., Jabeen, R., Mustafa, S., Siddique, N., Liaqat, A., \& Robab, I. (2019). Attitudes, instructional practices and difficulties faced by English teachers while teaching through 'Quality drive'. English Language Teaching, 12(5), 79. doi:10.5539/elt.v12n5p79

[20] Mahboob, A. (2002). No English, no future: Language policy in Pakistan. In S. G. Obeng \& B. Hartford (Eds.), Political independence with linguistic servitude: The politics about languages in the developing world (pp. 1-42). New York: Nova Publishers.

[21] Menken, K., \& García, O. (Eds.). (2010). Negotiating language education policies: Educators as policymakers. Routledge.

[22] Menken, K. (2008). English learners left behind: Standardized testing as language policy. Clevedon, UK: Multilingual Matters.

[23] Mohanty, A., Panda, M., Pal, R., Menken, K., \& Garcia, O. (2010). Language policy in education and classroom practices in India. Negotiating language policies in schools: Educators as policymakers, 211231.

[24] National Education Policy 2009. (2009). Retrieved from Ministry of Education Government of Pakistan website: http://itacec.org/document/2015/7/National _Education_Policy_2009.pdf
[25] National Education Policy 2017. Retrieved from Ministry of Federal Education and Professional Training Government of Pakistan website: http://www.mofept.gov.pk/SiteImage/Polic y/Draft\%20National\%20Educaiton\%20Poli cy\%202017.pdf

[26] PITB technology board. (2020). Measuring student learning outcomes, cost effectively.. Retrieved from https://pitb.gov.pk/mslo

[27] Punjab information technology board. (2020). LND | About us. Retrieved June 27, 2020 , from https://open.punjab.gov.pk/lnd/reports/abou tus

[28] School education department. (2018). The new deal 2018-2023. Retrieved from School education department website: http://itacec.org/document/2019/april/The _ New_Deal2018.pdf

[29] School Education Department. (2020). Programme Monitoring and Implementation Unit. Retrieved from pmiu.pitb.gov.pk/home/index

[30] Strauss, A., \& Corbin, J. M. (1998). Basics of qualitative research: Techniques and procedures for developing grounded theory. SAGE Publications.

[31] Tauqir, T. \& Akram, K. (2020). Linguistic analysis of language used in placards observed during Aurat March 2020. Competitive Linguistic Research Journal (CLRJ), 1(1), 1-16.

[32] UNESCO. (2019, July 3). Leading SDG 4 Education 2030. Retrieved from https://en.unesco.org/themes/education2030 -sdg4

[33] United States Agency for International Development (USAID). (2008). Education Sector Reform Assistance (ESRA) Program: End-of-Project Report. Retrieved from http://pdf.usaid.gov/ pdf_docs/PDACL186.pdf 